\title{
Papers
}

\section{Oral contraceptives and myocardial infarction: results of the MICA case-control study}

Nicholas Dunn, Margaret Thorogood, Brian Faragher, Linda de Caestecker, Thomas M MacDonald, Charles McCollum, Simon Thomas, Ronald Mann

\begin{abstract}
Objectives To determine the association between myocardial infarction and use of different types of oral contraception in young women.

Design Community based case-control study. Data from interviews and general practice records. Setting England, Scotland, and Wales. Participants Cases $(n=448)$ were recruited from women aged between 16 and 44 who had suffered an incident myocardial infarction between 1 October 1993 and 16 October 1995. Controls $(n=1728)$ were women without a diagnosis of myocardial infarction matched for age and general practice.
\end{abstract}

Main outcome measures Odds ratios for myocardial infarction in current users of all combined oral contraceptives stratified by their progestagen content compared with non-users; current users of third generation versus second generation oral contraceptives.

Results The adjusted odds ratio for myocardial infarction was 1.40 (95\% confidence interval 0.78 to 2.52) for all combined oral contraceptive users, 1.10 (0.52 to 2.30) for second generation users, and 1.96 (0.87 to 4.39) for third generation users. Subgroup analysis by progestagen content did not show any significant difference from 1 , and there was no effect of duration of use. The adjusted odds ratio for third generation users versus second generation users was 1.78 ( 0.66 to 4.83$) .87 \%$ of cases were not exposed to an oral contraceptive, and $88 \%$ had clinical cardiovascular risk factors or were smokers, or both. Smoking was strongly associated with myocardial infarction: adjusted odds ratio 12.5 (7.29 to 21.5$)$ for smoking 20 or more cigarettes a day.

Conclusions There was no significant association between the use of oral contraceptives and myocardial infarction. The modest and non-significant point estimates for this association have wide confidence intervals. There was no significant difference between second and third generation products.

\section{Introduction}

Recent studies on the association between use of oral contraceptives and myocardial infarction have suggested that any risk is confined to women with known cardiovascular risk factors. ${ }^{1-3}$ Reported odds ratios vary between 1.67 and 5.01 for comparison of current users of all types of combined oral contraceptive versus nonusers. Only one study, however, had sufficient power to report on the variation in risk between different types of oral contraceptive. ${ }^{3}$ This study found an odds ratio of $0.28(95 \%$ confidence interval 0.09 to 0.86$)$ for current users of third generation versus second generation oral contraceptives. Third generation oral contraceptives were defined as those containing the progestagens gestodene and desogestrel combined with ethinyloestradiol and second generation as containing the progestagens levonorgestrel and norethisterone combined with less than $50 \mu \mathrm{g}$ of ethinyloestradiol. The MICA study was designed to investigate whether the risk of myocardial infarction was influenced by oral contraceptive use overall and to study in more detail the effect of different types of oral contraceptives among women in England, Scotland, and Wales.

\section{Methods}

The research protocol for this study has been published elsewhere. ${ }^{4}$ This was a community based, retrospective case-control study undertaken in the population of England, Scotland, and Wales.

Cases-Women were eligible as cases if they were aged 16-44 and had suffered an incident myocardial infarction between 1 October 1993 and 16 October 1995. Exclusion criteria were a history of myocardial infarction, pregnancy in the 6 weeks before the date of the myocardial infarction, or a history of menopause, hysterectomy, oophorectomy, and breast or ovarian cancer. Cases were identified from hospital inpatient episode statistics and the deaths register of the Office for National Statistics for all England and Wales and from the Information and Statistics division of the Department of Health or the registrar general's office in Scotland. International classification of diseases, 9th revision (ICD-9) code 410 or 10th revision (ICD-10) code 121 were used as identifiers of acute myocardial infarction. A validation study in Tayside, Scotland, showed $67 \%$ sensitivity and $100 \%$ specificity in using only these codes for identifying the cases. ${ }^{5}$ Diagnostic information for each potential case was extracted from the hospital notes, and these data were submitted to a

\author{
Drug Safety \\ Research Unit, \\ Bursledon Hall, \\ Southampton \\ SO31 1AA \\ Nicholas Dunn, \\ senior research fellow \\ Ronald Mann, \\ director \\ London School of \\ Hygiene and \\ Tropical Medicine, \\ London WC1 6FH \\ Margaret \\ Thorogood, \\ reader in public \\ health and preventive \\ medicine \\ Department of \\ Organisational \\ Psychology, \\ Manchester School \\ of Management, \\ UMIST, PO Box 88 , \\ Manchester \\ M60 1QD \\ Brian Faragher, \\ senior lecturer \\ Department of \\ Public Health, \\ Greater Glasgow \\ Health Board, \\ Dalian House, \\ PO Box 15327, \\ Glasgow G3 8YU \\ Linda de \\ Caestecker, \\ consultant in public \\ health medicine \\ Medicines \\ Monitoring Unit, \\ Department of \\ Clinical \\ Pharmacology and \\ Therapeutics, \\ Ninewells Hospital \\ Medical School, \\ Dundee DD1 9SY \\ Thomas M \\ MacDonald, \\ professor of clinical \\ pharmacology and \\ pharmacoepidemiology \\ continued over
}

BMJ 1999;318:1579-84 
Department of Surgery, South Manchester

University Hospital,

West Didsbury,

Manchester

M20 8LR

Charles McCollum,

professor of surgery

Wolfson Unit of

Clinical

Pharmacology,

University of

Newcastle,

Newcastle upon

Tyne NE2 4HH

Simon Thomas,

senior lecturer

Correspondence to:

Dr Dunn

ndunn@dsru.

u-net.com panel of three cardiologists, blinded to exposure status, for confirmation of diagnosis. Criteria for diagnosis were according to the World Health Organisation, with inclusion of the case depending on a majority decision of the diagnosis as being "definite" or "possible." Cases in which the woman died before reaching hospital or before investigations had been done were validated on the result of the necropsy findings. Those without necropsy were excluded. Women were interviewed in the community by using a structured questionnaire, after consent was obtained from the general practitioner and the patient. For women who died we interviewed a proxy (husband or a close relative).

Controls-Control women were selected from the general practice with which the index woman was registered at the time of her myocardial infarction. They were closely matched by age: each general practitioner provided a list of women with date of birth closest to the index woman's (six older and six younger), and we interviewed the four controls with closest date of birth (two older and two younger) from among those who consented.

Interview data-The interview included questions on medical history of cardiovascular risk factors, obstetric history (including history of high blood pressure), use of contraception in the 5 years before the myocardial infarction (recorded in a calendar), drug history, family history of premature cardiovascular disease, and socioeconomic status (by employment history of interviewee and partner). Current use of oral contraceptives was defined as use within 3 months of the date of myocardial infarction to enable direct comparisons with results from WHO and transnational studies. ${ }^{13}$ Interviews were carried out between December 1996 and February 1998 and thus the length of recall varied between 14 months and 51 months.

Risk factors-Risk factors and exposure data (oral contraceptive use, blood pressure, smoking, lipid concentrations, and family history) were validated by checking against the interviewee's general practitioner record or occasionally against records from family planning clinics. We calculated odds ratios using three different measures of exposure: interview data, general practitioner record data, and a compromise with exposure data taken from general practitioner records when the two sources disagreed on the type of oral

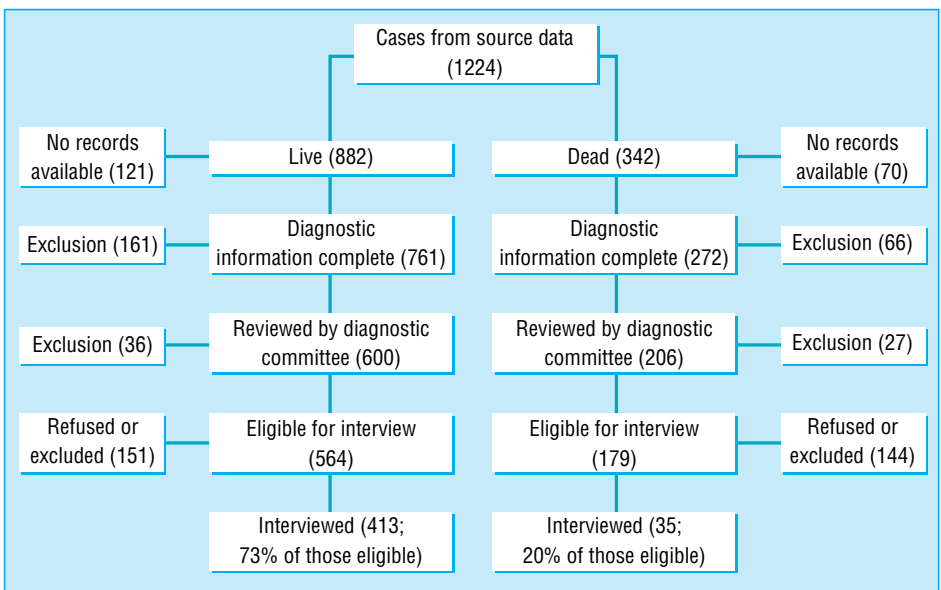

Case accrual and interview rates ( ${ }^{\star} 30$ women died at time of myocardial infarction and five died subsequently) contraceptive and interview data when there was disagreement on whether or not there was any current exposure to oral contraception.

Control of observer bias-All research assistants were trained in a standardised technique and were issued with a standard field manual. They were quality controlled throughout the study by means of accompanied and taped interviews.

Statistical power-With data from 448 cases and 1728 controls available for statistical evaluation and a prevalence of exposure to third generation oral contraceptives of $3.7 \%$ in the controls the power of this study to detect an odds ratio of 2 for third generation users versus no use was $81 \%$ at the $5 \%$ significance level. The power for second generation oral contraceptive users (exposure $7.2 \%$ ) versus no use was $96 \%$.

Statistical analysis-We fitted conditional logistic regression models with STATA (StataCorp, Texas, release 5, 1997) with outcome (case-control status) as the dependent variable. Unadjusted univariate odds ratios were estimated for category of contraceptive use and for all potential confounding variables. In a first, planned, multivariate analysis a stepwise backward elimination procedure was carried out to identify those potential confounding variables which were independently related to outcome by using an arbitrary significance level for expulsion from the model of $\mathrm{P}<0.05$. The odds ratios for category of contraceptive use were then adjusted for those confounding factors which entered the stepwise regression model. These are referred to as "select." In a second multivariate analysis we adjusted the odds ratios for contraceptive use category for all potential confounding factors. These are referred to as "full." Both analyses are presented. Finally, unconditional logistic regression models were fitted to selected subgroups of cases and controls, again with STATA.

\section{Results}

\section{Incidence rate}

On the basis of 1224 cases identified from source data (see figure), the incidence rate of myocardial infarction was 0.5 per 1000 women years.

\section{Cases and controls}

We interviewed 413 women who had experienced myocardial infarction (index women) and 35 surrogates in cases when the index woman had died, representing $60.4 \%$ of the total eligible cases. There was a large difference in the interview rate between surviving index women and surrogates (figure). A total of 1728 control women were interviewed, giving a mean of 3.86 controls per case. Age matching between cases and controls was good, the median age difference being only 18 days (table 1 ). We validated the data from 436 $(97 \%)$ cases and $1716(99 \%)$ controls with general practitioner or family planning records.

\section{Risk factors}

Table 1 shows the distribution of the potential confounders between the cases and controls. Most of these covariates were shown to be associated with an increased risk of myocardial infarction: smoking, diabetes mellitus, and history of angina having the 
largest effects. In $88 \%$ of cases (versus $36 \%$ of controls) we found one or more cardiovascular risk factors. In particular, $80 \%$ (360) of the index women were smokers compared with $30 \%$ (520) of controls, and there was a clear gradient of risk with increasing number of cigarettes smoked per day. The population attributable fraction for smoking in the year before the myocardial infarction was $73 \%$. Consumption of alcohol, taking regular exercise to keep fit, and being in paid work in the past year were all associated with a decreased risk of myocardial infarction.

\section{Exposure to oral contraceptives}

Table 2 shows the data on exposure to oral contraceptives in the 3 months before the date of the myocardial infarction. From the subject interviews, $87 \%$ of index women were not taking an oral contraceptive in this time period.

\section{Univariate analysis}

Although most of the point estimates of the unadjusted odds ratios were below 1 , the $95 \%$ confidence intervals predominantly include 1 (table 2 ). We further subdivided the third generation oral contraceptives that contain desogestrel into two classes: those with low dose $(20 \mu \mathrm{g})$ and those with standard dose $(30 \mu \mathrm{g})$ ethinyloestradiol. The odds ratio for low dose was 0.46 (95\% confidence interval 0.13 to 1.55$)$ and that for standard dose was 1.57 ( 0.59 to 4.17 ), but these were based on only three and six cases, respectively.

Stratification by current smoking habit (nonsmokers, all smokers, and smoking $>20$ cigarettes a day) produced odds ratios which were not significantly different from 1 for any classification of oral contraceptive.

\section{Multivariate analysis}

Table 3 shows the odds ratios from the "select" model adjusted for number of cigarettes smoked a day, diabetes mellitus, family history of ischaemic heart disease, other drugs taken in past year, body mass index, history of hypertension, history of angina, and whether or not blood pressure was taken in past year. Adjustment tended to increase the odds ratios, but none was significant. There was no effect of duration of use of oral contraceptives. There were some differences in the point estimates of odds ratios derived from the two data sources (interview and general practitioner record data), but the $95 \%$ confidence intervals overlapped.

Table 3 also shows the odds ratios from the "full" model-that is, adjusted for all the factors in the "select" model, plus all additional variables examined in the univariate analysis (table 1). The odds ratios are all higher than for the select model but with wider confidence intervals. Adjusted odds ratios for third generation versus second generation users were as follows: from patient interview data 2.06 (0.77 to 5.50), from general practitioner record data 1.41 (0.54 to 3.70), and from interview and general practitioner data combined 1.78 (0.66 to 4.83$)$.

\section{Discussion}

Myocardial infarction is rare in this age group of women. The point estimates suggest that the risk of myocardial infarction is increased slightly by the use of
Table 1 Conditional odds ratios for characteristics of women who suffered myocardial infarction (cases) and control women. Figures are numbers (percentage) of women unless stated otherwise

\begin{tabular}{|c|c|c|c|}
\hline Variable & $\begin{array}{l}\text { Cases } \\
(\mathrm{n}=448)\end{array}$ & $\begin{array}{l}\text { Controls } \\
(n=1728)\end{array}$ & $\begin{array}{l}\text { Univariate odds ratio } \\
(95 \% \mathrm{CI})\end{array}$ \\
\hline Median (interquartile range) age (years) & $40.6(37.4-42.9)$ & $40.7(37.4-42.9)$ & \\
\hline \multicolumn{4}{|l|}{ Medical history: } \\
\hline Hypertension & $81(18.1)$ & $88(5.1)$ & 4.23 (3.03 to 5.89$)$ \\
\hline Chronic bronchitis & $34(7.6)$ & $36(2.1)$ & 4.26 (2.57 to 7.07$)$ \\
\hline Stroke & $10(2.2)$ & $7(0.4)$ & 5.14 (1.92 to 13.8$)$ \\
\hline Heart disease & $11(2.5)$ & $31(1.8)$ & 1.24 (0.59 to 2.58$)$ \\
\hline Angina & $22(4.9)$ & $10(0.6)$ & 9.27 (4.26 to 20.2$)$ \\
\hline Hyperlipidaemia & $34(7.6)$ & $51(3.0)$ & 2.68 (1.70 to 4.23$)$ \\
\hline Diabetes mellitus & $52(11.6)$ & $17(1.0)$ & 14.1 (7.82 to 25.5$)$ \\
\hline Cardinal risk factors ${ }^{*}$ & $147(32.8)$ & $140(8.1)$ & 5.80 (4.38 to 7.67$)$ \\
\hline \multicolumn{4}{|l|}{ Blood pressure measured: } \\
\hline In past year & $263(58.7)$ & $985(57.0)$ & $0.97(0.77$ to 1.23$)$ \\
\hline Not known & $47(10.5)$ & $239(13.8)$ & $0.71(0.49$ to 1.03$)$ \\
\hline \multicolumn{4}{|l|}{ Obstetric history: } \\
\hline Ever pregnant & $399(89.1)$ & $1521(88.0)$ & $1.17(0.82$ to 1.66$)$ \\
\hline Multiparity (>4 live births) & $22(4.9)$ & $39(2.3)$ & $2.46(1.33$ to 4.54$)$ \\
\hline Pre-eclampsia & $146(32.6)$ & $396(22.9)$ & 1.64 (1.30 to 2.06$)$ \\
\hline Sterilisation & $129(28.8)$ & $355(20.5)$ & 1.63 (1.27 to 2.08$)$ \\
\hline \multicolumn{4}{|l|}{ Other medications: } \\
\hline Steroids (oral/inhaler/topical) & $45(10.0)$ & $85(4.9)$ & 2.19 (1.49 to 3.22$)$ \\
\hline Other hormones & $23(5.1)$ & $71(4.1)$ & 1.25 (0.76 to 2.07$)$ \\
\hline Psychotropic drugs & $56(12.5)$ & $117(6.8)$ & 2.03 (1.43 to 2.88$)$ \\
\hline Other, non-cardiovascular drugs & $157(35.0)$ & $252(14.6)$ & 3.18 (2.49 to 4.06$)$ \\
\hline \multicolumn{4}{|l|}{ Family history: } \\
\hline Ischaemic heart disease & $243(54.2)$ & $494(28.6)$ & 3.04 (2.44 to 3.79$)$ \\
\hline Hypertension & $140(31.3)$ & $486(28.1)$ & 1.17 (0.94 to 1.47$)$ \\
\hline Hyperlipidaemia & $63(14.1)$ & $151(8.7)$ & 1.74 (1.27 to 2.39$)$ \\
\hline \multicolumn{4}{|l|}{ Personal history: } \\
\hline Mean (SD) body mass index $\mathrm{kg} / \mathrm{m}^{2}$ & $28.13(6.57)$ & $25.37(4.99)$ & $1.09(1.07$ to 1.11$) \dagger$ \\
\hline Smoked in past year & $360(80.4)$ & $520(30.1)$ & 9.99 (7.58 to 13.2$)$ \\
\hline Ever smoked cigarettes & $394(87.9)$ & $899(52.0)$ & 6.88 (5.05 to 9.36$)$ \\
\hline \multicolumn{4}{|l|}{ Cigarettes/day smoked in past year: } \\
\hline $1-9$ & $14(3.1)$ & $58(3.4)$ & 2.54 (1.30 to 4.94$)$ \\
\hline $10-19$ & $93(20.8)$ & $214(12.4)$ & 6.27 (4.40 to 8.94$)$ \\
\hline$\geqslant 20$ & $253(56.5)$ & $247(14.3)$ & 16.5 (12.0 to 22.8$)$ \\
\hline \multicolumn{4}{|l|}{ Alcohol intake (days/week): } \\
\hline 1 & $85(19.0)$ & $414(24.0)$ & $0.60(0.45$ to 0.80$)$ \\
\hline $2-3$ & $88(19.6)$ & $467(27.1)$ & 0.54 (0.41 to 0.72$)$ \\
\hline $4-7$ & $45(10.0)$ & $161(9.3)$ & $0.79(0.54$ to 1.14$)$ \\
\hline \multicolumn{4}{|l|}{ Takes exercise to keep fit (hours/week): } \\
\hline$\geqslant 1$ & $46(10.3)$ & $273(15.8)$ & 0.45 (0.32 to 0.64$)$ \\
\hline$>1-2$ & $35(7.8)$ & $291(16.8)$ & $0.33(0.22$ to 0.48$)$ \\
\hline$>2-3$ & $38(8.5)$ & $173(10.1)$ & 0.55 (0.37 to 0.81$)$ \\
\hline$>3$ & $64(14.3)$ & $269(15.6)$ & $0.60(0.43$ to 0.82$)$ \\
\hline Subject employed in past year & $287(64.1)$ & $1372(79.4)$ & $0.46(0.36$ to 0.57$)$ \\
\hline
\end{tabular}

${ }^{*}$ Any one of hypertension, hyperlipidaemia, angina, or diabetes mellitus.

fFor 1 unit increase in body mass index.

oral contraceptives, although adjustment for a large number of confounders introduced some uncertainty in the risk estimates, as shown by wide $95 \%$ confidence intervals. The point estimates were greater for third than for second generation oral contraceptives, but the differences observed were not significant.

Smoking was an important risk factor (the population attributable fraction being $73 \%$ ), and other cardiovascular risk factors were also important. In line with the results from the WHO study ${ }^{1}$ and the transnational study, ${ }^{3}$ among those who were current users of oral contraceptives the absence of a blood pressure check in the year preceding the index woman's myocardial infarction showed a positive association with myocardial infarction, although this was not significant (odds ratio $2.07 ; 0.81$ to 5.30$)$. The positive association 
Table 2 Unadjusted conditional odds ratios by source of information on oral contraceptive use in women who suffered myocardial infarction (cases) and control women

\begin{tabular}{|c|c|c|c|c|c|}
\hline Progestagen group & $\begin{array}{c}\text { No }(\%) \\
\text { of cases } \\
\left(\mathrm{n}=448^{*}\right)\end{array}$ & $\begin{array}{c}\text { No }(\%) \\
\text { of controls } \\
\left.\text { ( } n=1728^{*}\right)\end{array}$ & $\begin{array}{l}\text { Unadjusted odds ratios by } \\
\text { interview data }(95 \% \mathrm{CI})\end{array}$ & $\begin{array}{l}\text { Unadjusted odds ratios by } \\
\text { GP record data }(95 \% \mathrm{CI})\end{array}$ & $\begin{array}{l}\text { Unadjusted odds ratios by } \\
\text { data combined }(95 \% \mathrm{Cl}) \dagger\end{array}$ \\
\hline No oral contraception & $386(86.7)$ & $1467(85.0)$ & 1.00 & 1.00 & 1.00 \\
\hline 2nd and 3rd generation & $40(9.2)$ & $180(10.7)$ & 0.79 (0.53 to 1.16$)$ & 0.75 (0.50 to 1.11$)$ & 0.78 (0.52 to 1.18$)$ \\
\hline 2nd generation & $20(4.5)$ & $119(7.1)$ & $0.58(0.35$ to 0.98$)$ & $0.78(0.47$ to 1.29$)$ & 0.73 (0.43 to 1.25$)$ \\
\hline Norethisterone & $2(0.4)$ & $14(0.8)$ & 0.49 (0.11 to 2.23 ) & $1.53(0.39$ to 5.97$)$ & $1.25(0.25$ to 6.19$)$ \\
\hline Levonorgestrel & $18(4.0)$ & $105(6.1)$ & 0.59 (0.34 to 1.03$)$ & $0.72(0.42$ to 1.23$)$ & 0.69 (0.39 to 1.22$)$ \\
\hline 3rd generation & $20(4.5)$ & $61(3.5)$ & 1.20 (0.7. to 2.06) & 0.71 (0.40 to 1.24) & 0.85 (0.48 to 1.51$)$ \\
\hline Gestodene & $11(2.5)$ & $24(1.4)$ & 1.72 (0.82 to 3.62$)$ & 1.10 (0.51 to 2.35$)$ & 1.33 (0.61 to 2.89 ) \\
\hline Desogestrel & $9(2.0)$ & $37(2.1)$ & 0.86 (0.41 to 1.84$)$ & 0.48 (0.22 to 1.09$)$ & $0.58(0.25$ to 1.31$)$ \\
\hline Progestagen only & $9(2.0)$ & $49(2.8)$ & 0.69 (0.34 to 1.43$)$ & 0.80 (0.44 to 1.43 ) & 0.80 (0.41 to 1.55$)$ \\
\hline
\end{tabular}

${ }^{*}$ No information on oral contraceptive use obtained from three cases and two controls. There were 10 index women and 30 controls taking other oral contraceptives: type unknown, norgestimate, high dose oestrogen (50 mg mestranol), or cyproterone (interview data).

tWith interview data when disagreement on current exposure or not, GP record data when disagreement on type of oral contraceptive.

between multiparity and myocardial infarction has been reported before ${ }^{7}$ as has that with pre-eclampsia. ${ }^{1}$ The beneficial effect of consumption of alcohol is in keeping with results of other studies, ${ }^{8}$ as is the benefit of exercise and being in employment in the past year. ${ }^{9}$

\section{Potential bias}

Possible weaknesses of this study were low interview rates, misclassification of exposure, and selection bias. We interviewed $73 \%$ of the women who survived myocardial infarction but achieved proxy interviews for only $20 \%$ of those who died, which may have introduced a bias if, for example, certain types of oral contraceptive were particularly liable to cause sudden death from myocardial infarction. This does not seem likely as oral contraceptives were not found to be a significant risk factor in this study, but it cannot be entirely discounted. Recall bias may have occurred because we asked interviewees to recall contraceptive habits. The adverse publicity about third generation oral contraceptives generated by the "Dear Doctor" letter from the United Kingdom Committee on Safety of Medicines in October 1995 may have biased responses to our questions, although, whenever possible, interviewees were blinded to the main objective of the study. Also, we provided photographs of all marketed oral contraceptives to increase the accuracy of recall. Furthermore, we validated the exposure data from written records, and the $\kappa$ score for agreement in exposure data between the two sources was 0.8 for both cases and controls. As shown in tables 2 and 3 there were some differences in odds ratios with the two different sources, but overall the measures of effect were similar, and the "compromise" odds ratios represent our best estimate of the true effect. Some effect of selection bias is possible because controls were women who responded to a request to participate, and such women may not be representative of the population, but on average it was necessary to approach only 6.6 (range 4-26) of the closest age matched controls.

\section{Relevance of results}

The importance of the MICA study is that it had sufficient power to examine the effects of oral contraceptives with differing progestagen content on the incidence of myocardial infarction with very close age matching between cases and controls. Our results do not agree with those of the European transnational study, ${ }^{3}$ although the United Kingdom results from that study and the present study show considerable overlap and are compatible within the bounds of random error. Other studies have been hampered by small numbers of participants exposed to oral contraceptives but generally their results also suggest that there is no difference in risk of myocardial infarction between different preparations. $^{12}{ }^{10}$ Although the WHO study reported an adjusted odds ratio of 5.01 (2.54 to 9.90) for European oral contraceptive users overall compared with non-users, ${ }^{1}$ and this contrasts with an odds ratio of 1.40 in this study, the populations studied were quite different. The WHO study recruited 55\% of their cases from Eastern Europe, where there may be inadequate screening for risk factors among oral contraceptive users, and it is pertinent

Table 3 Adjusted conditional odds ratios (95\% confidence intervals) by source of information on oral contraceptive use in women who suffered myocardial infarction (cases) and control women

\begin{tabular}{|c|c|c|c|c|c|c|}
\hline \multirow[b]{2}{*}{ Progestogen group } & \multicolumn{3}{|c|}{ Select model* } & \multicolumn{3}{|c|}{ Full model } \\
\hline & Subject interview & GP record form & Interview and GP† & Subject interview & GP record form & Interview and GP† \\
\hline No oral contraception & 1.00 & 1.00 & 1.00 & 1.00 & 1.00 & 1.00 \\
\hline 2nd and 3rd generation & $1.23(0.70$ to 2.16$)$ & 1.30 (0.75 to 2.25$)$ & 1.22 (0.69 to 2.14$)$ & 1.50 (0.83 to 2.70$)$ & 1.50 (0.85 to 2.65$)$ & 1.40 (0.78 to 2.52$)$ \\
\hline Norethisterone & $0.75(0.06$ to 9.03$)$ & $2.56(0.39$ to 16.9$)$ & $1.83(0.15$ to 22.7$)$ & $0.92(0.07$ to 11.7$)$ & $3.14(0.44$ to 22.6$)$ & 2.26 (0.16 to 32.2$)$ \\
\hline Levonorgestrel & $0.95(0.46$ to 1.97$)$ & $1.06(0.52$ to 2.17$)$ & $0.93(0.45$ to 1.95$)$ & $1.13(0.53$ to 2.41$)$ & $1.18(0.56$ to 2.48$)$ & 1.03 (0.48 to 2.23$)$ \\
\hline Desogestrel & $1.57(0.55$ to 4.47$)$ & $1.11(0.38$ to 3.23$)$ & 1.20 (0.40 to 3.57$)$ & $1.98(0.70$ to 5.57$)$ & $1.37(0.47$ to 4.06$)$ & $1.51(0.50$ to 4.57$)$ \\
\hline Progestogen only & $0.57(0.21$ to 1.58$)$ & 1.15 (0.54 to 2.49$)$ & $1.23(0.52$ to 2.91$)$ & $0.68(0.23$ to 2.04$)$ & 1.36 (0.60 to 3.05$)$ & $1.48(0.60$ to 3.65$)$ \\
\hline
\end{tabular}

*Adjusted for current cigarette smoking, body mass index, blood pressure measured in previous year, diabetes mellitus, angina, hypertension, family history of ischaemic heart disease, and use of other drugs.

tInterview data used when disagreement on current exposure or not, GP record data used when disagreement on type of oral contraceptive. 
that the odds ratio for the subset of United Kingdom users was 2.10 (0.63 to 7.07), which is similar to our results. Comparison of the MICA study with similar studies carried out in the 1980s, which found odds ratios for current use of oral contraceptives varying between 1.2 and $3.5,{ }^{11}{ }^{12}$ is difficult because of changes in the formulations of the pills and because of probable improvements in routine medical care. The fact that most women with myocardial infarction in the present study were not taking any oral contraception suggests that doctors were cautious in their prescribing habits for older women who might be at risk. Our results for smoking and other cardiovascular risk factors agree with those of all the recent studies on this topic. These factors are of overriding importance in the aetiology of myocardial infarction in this age group and in comparison the use of oral contraception makes little or no difference.

We thank all the women and next of kin who agreed to be interviewed, hospital records staff, general practitioners and surgery staff, and those who worked on the MICA project as follows: National Centre staff: Ann Arscott (national project manager), Jan Phillips (administrator), Susan Jay (quality control officer), Greg Gallagher and Caroline Keal (data entry clerks), Annette Kinsella (data programmer), Gretl McHugh (epidemiological support), Gill Mein and Deborah Curle (study advisors); Southampton Centre staff: Penny Nettelfield, Julie Pring, Rachael Green, Lesley Foulkest, Julie Richardson, Shona Burman-Roy, Jo Lockett, Liz Bale, and Yvonne Egan-Davidson (research assistants), Dr Derek Waller (local diagnostic committee); Manchester Centre staff: Mr Harvey Chant (medical coordinator), Jane Richardson (project manager), Jill Carley, Linda Robinson, Helen Shea, Tamsin Warner, Joanne Watson, and Heather Youngson (research assistants), Jane Booth (secretary), Dr Nicholas Brooks (local diagnostic committee); Glasgow Centre staff: Hilary Davison (project manager), Edith Hamilton, Sheena Mitchell, Susan Brogan, and Margaret Carlin (research assistants), Anne Currie (secretary), Professor Ross Lorimer (local diagnostic committee). Newcastle Centre staff: Judy Bland and Lyn Cassidy (research assistants), Dr Gary Ford (local diagnostic committee); National Diagnostic Committee: Dr Richard Jones, Professor David de Bono; Scientific Review Board: Miss Angela Mills, Professor Martin Vessey, Professor Michael Langman, Dr Kenneth MacRae, Professor David de Bono.

Contributors: ND and RM (principal investigator) initiated the study and wrote the protocol with MT, LdeC, CMcC, TMMacD, and ST. MT was principal scientific advisor. BF carried out the statistical analysis. All the authors contributed to the revision of the paper, which was originally drafted by ND. All the authors sat on the steering committee throughout the study. RM is the guarantor for the study.

\section{Key message}

- There is no evidence of a difference between second and third generation oral contraceptives on risk of myocardial infarction

- There is no significantly increased risk of myocardial infarction in users of oral contraceptives

- Of women aged under 45 years who suffered a myocardial infarction, $87 \%$ were not taking any oral contraceptive

- Of women who suffered myocardial infarction, $88 \%$ had one or more known cardiovascular risk factors

- Young women who wish to preserve cardiovascular health should be advised to stop smoking, above all else

Funding: Unconditional grant from NV Organon and Schering AG.

Competing interests: None declared.

1 WHO Collaborative Study of Cardiovascular Disease and Steroid Hormone Contraception. Acute myocardial infarction and combined oral contraceptives: results of an international case-control study. Lancet $1997 ; 349: 1202-9$

2 Sydney S, Pettiti DB, Quesenbery CP, Klatsky AL, Ziel HK, Wolf S. Myocardial infarction in users of low dose oral contraceptives. Obstet Gynecol 1996:88:939-44.

3 Lewis MA, Heinemann LAJ, Spitzer WO, MacRae KD, Bruppacher R, on behalf of Trans-National Research Group on Oral Contraceptives and the Health of Young Women. The use of oral contraceptives and the occurrence of acute myocardial infarction in young women. Contraception 1997;56:129-40.

4 Dunn NR, Thorogood M, de Caestecker L, Mann RD. Myocardial infarction and oral contraceptives, a retrospective case-control study in England and Scotland (MICA study). Pharmacoepidemiol Drug Safety 1997;6:283-9.

5 McAlpine R, Pringle S, Pringle T, Lorimer R, MacDonald T. A study to determine the sensitivity and specificity of hospital discharge diagnosis data used in the MICA study. Pharmacoepid Drug Safety 1998;7:311-8.

6 WHO Collaborative Study of Cardiovascular Disease and Steroid Hormone Contraception. A multinational case-control study of cardiovascular disease and steroid hormone contraceptives. J Clin Epidemiol 1995; 48:1513-47.

7 Oliver MF. What is the difference between men and women? In: Oliver MF, Vedin A, Wilhelmsson C, eds. Myocardial infarction in women. Edinburgh: Churchill Livingstone 1986:215-21.

8 Tunstall-Pedoe H, Woodward M, Tavendale R, A'Brook R, McCluskey MK. Comparison of the prediction by 27 different factors of coronary heart disease and death in men and women of the Scottish heart health study: cohort study. BMJ 1997;315:722-9.

9 Rich-Edwards JW, Manson JE, Hennekens CH, Buring JE. The primary prevention of coronary heart disease in women. $N$ Engl J Med 1995;332:1758-66.

10 Jick H, Jick SS, Myers MW. Risk of acute myocardial infarction and low dose combined oral contraceptives. Lancet 1996;347:627-8.

11 Rosenberg L, Palmer JR, Lesko SM, Shapiro S. Oral contraceptive use and the risk of myocardial infarction. Am J Epidemiol 1990;131:1009-16.

12 La Vecchia C, Fransceschi S, De Carli A, Pampallona S, Tognoni G. Risk factors for myocardial infarction in young women. Am J Epidemiol 1987;125:832-43.

(Accepted 25 February 1999)

\section{Commentary: Oral contraceptives and myocardial infarction: reassuring new findings}

Øjvind Lidegaard

One of the main challenges in pharmacoepidemiology is the assessment of the risk of rare but severe side effects. Since oral contraceptives were introduced in the early 1960s the most important concern has been the possible increased risk of thromboembolic disease in users. Few drugs have been the object of such intensive epidemiological research, the outcome of which has provided clinicians with detailed information about risks not only of specific thrombotic diseases but also important non-contraceptive benefits from the pill.
The MICA study by Nicholas Dunn et al is an important reassuring contribution to the assessment of the risk of acute myocardial infarction in users of oral contraceptives and is one of several recent examples of large scale epidemiological studies conducted within a relatively short time frame.

There are four important clinical messages from the study. Firstly, in $88 \%$ of cases the women had one or more classic cardiovascular risk factors: $80 \%$ were smokers and not less than $73 \%$ of acute myocardial
Department of Obstetrics and Gynaecology, Herlev Hospital, University of Copenhagen, DK 2730 Herlev, Denmark Øjvind Lidegaard, assistant professor 
infarction in women of reproductive age could be prevented if all women stopped smoking. Secondly, the risk of infarct was not significantly increased in users of combined oral contraceptives compared with nonusers. Thirdly, there was no significant difference in the risk of acute myocardial infarct among users of different types of oral contraceptives according to progestagen type. And, finally, adjustment for relevant confounders in the multivariate analysis increased the risk of the older "2nd generation" pills (with levonorgestrel) and decreased the risk of the newer "3rd generation" pills (with desogestrel or gestodene), suggesting a differential prescription of older and newer pills to women at an anticipated increased risk of thrombotic diseases.

At the same time, with recognition that epidemiological studies are the strongest instrument to assess risks and benefits of different types of drugs, the new study also illustrates that observational studies (which for good reasons and in contrast with clinical trials are not randomised) are very sensitive to different kind of bias; recall bias and selection bias being the most important potential biases to account for. In the MICA study the risk ratio between 3rd and 2nd generation oral contraceptives was 1.14 on the basis of records from general practitioners but 1.74 (70\% higher) when the estimate was based on the women's recall, suggesting that some kind of recall bias was present, despite relevant measures taken to diminish it.

The influence of selection of patients and controls in epidemiological case-control studies is illustrated by the different measures of risk of thrombotic diseases reached in different studies, even in the same region during about the same period. The WHO multicentre study (198 cases) found a fivefold increased risk of acute myocardial infarction in current users of oral contraceptives in Europe but an increase of only 2.6-fold in women who had their blood pressure checked before prescription. ${ }^{1}$ The transnational study (140 cases) found a threefold increased risk in current users compared with hospital controls but a twofold risk compared with community controls and compared with users of oral contraceptives with 3rd generation progestogens, implying significantly less risk than for those oral contraceptives with 2nd generation progestogens. ${ }^{2}$

An important challenge to the investigators of epidemiological studies is to take relevant consideration of such biases and to try to assess the possible impact of these methodological circumstances. This attempt is the first opportunity for the lay press to effect a balanced message to the public and for health authorities not to overreact to new publications on rare side effects of oral contraceptives. Thereby unnecessary new pill scares may be prevented. Unfortunately, reassuring studies, such as the MICA study, are usually the object of less attention than they deserve.

1 World Health Organisation. Collaborative study on cardiovascular disease and steroid hormone contraception. Acute myocardial infarction and combined oral contraceptives: results of an international multicentre case-control study. Lancet 1997;349:1202-9.

2 Lewis M, Heinemann LAJ, Spitzer WO, MacRae KD, Bruppacher R. The use of oral contraceptives and the occurrence of acute myocardial infarction in young women. Contraception 1997;56:129-40.

\section{Corrections and clarifications}

Quebec faces severe pressure on casualty departments In this news article by David Spurgeon (27 February, p 556) the value of Canadian dollars was wrongly converted: \$C20m is roughly equivalent to $£ 8 m$ and \$US12m (not $£ 48 \mathrm{~m}$ and $\$ 77 \mathrm{~m}$ ).

Call to needle times after acute myocardial infarction Because of an editorial oversight, the letters by June Edhouse and colleagues and Matthew Hough and John Knighton (27 February, p 597) referred to patients being "thrombolysed" and "the opportunity to thrombolyse patients." These should, of course, have been changed to patients being "treated with thrombolytic drugs" and "the opportunity to provide thrombolytic treatment."

Reforming British primary care (again) This editorial by Trish Groves (20 March, pp 747-8) wrongly stated that primary care groups will not commission mental health services. The NHS Executive's Health Service Circular HSC 1998/198 makes clear that primary care groups will commission most mental health services-excluding the high cost, low volume specialised services such as

psychotherapies and forensic services-for adults, children, adolescents, and elderly people and drug and alcohol services.

Ordeals for the fetal programming hypothesis The subtitle of this editorial by Mervyn Susser and Bruce Levin (3 April, pp 885-6) should have read: "The hypothesis barely survives one ordeal but not another" rather than "The hypothesis largely survives one ordeal but not another."
Preventing injuries in children: cluster randomised controlled trial in primary care

This general practice paper by Denise Kendrick and colleagues (10 April, pp 980-3) contains three errors. The calculation of sample size was based on "a mean cluster size of 60 [not 60\%]" (first sentence, p 981); in table 3 (p 982) the number of children who received advice at the 18-24 month check should have been 535 rather than 35; and in table 4 (p 982) the number of children in the control group who had any medically attended injury should have been 330 rather than 220 .

Computer support for determining drug dose: systematic review and meta-analysis

In this information in practice paper by Robert Walton and colleagues (10 April, pp 984-90) the table stated, correctly, that computer support for control of ventricular arrhythmia with lignocaine led to increased infusion rate in the first hour (p 987). However, the units of infusion rate should have been $\mu \mathrm{g} / \mathrm{kg} / \mathrm{min}$ (not $\mathrm{mg} / \mathrm{kg} / \mathrm{min}$, as stated).

ABC of labour care: induction

This article by Geoffrey Chamberlain and Luke Zander (10 April, pp 995-8) includes a diagram titled "Inserting prostaglandin gel into upper vagina" (p 997). In fact, the diagram shows the gel being incorrectly inserted into the upper endocervical canal, next to the fetal membranes. Such a mistake usually causes a hypertonic uterine contraction, which may produce fetal distress and other complications. 